\title{
A randomized controlled trial with $\geq 5$ years of follow-up comparing minimally invasive and open transforaminal lumbar interbody fusion in disc herniation at single level
}

\author{
HAIEN ZHAO*, HAORAN GAO*, CHENGPEI ZHOU, SHU QIAN, \\ YIFANG YUAN, WEIGAO XUE and JIXIAN QIAN
}

Department of Orthopedics, Tangdu Hospital, The Fourth Military Medical University, Xi'an, Shaanxi 710038, P.R. China

Received January 7, 2018; Accepted January 14, 2019

DOI: $10.3892 /$ etm.2019.7368

\begin{abstract}
Minimally invasive transforaminal lumbar interbody fusion (m-TLIF) using transpedicular screws has various advantages over classical open (c-) TLIF. Up to date, comparative analyses of the TLIF procedures were following patients for $<5$ years. The objective of the present study was to compare the clinical effectiveness and complications of $\mathrm{m}$ and c-TLIF in patients with single-level disc herniation with $\geq 5$ years follow-up. Between June 2008 to July 2010,91 patients with single-level lumbar degeneration were recruited and were randomly divided into two groups: m-TLIF and c-TLIF. The analyzed outcome measurements included: Surgery duration, intraoperative blood loss, X-ray exposure time, T2 relaxation time in magnetic resonance imaging (MRI), visual analogue scale (VAS) scores, Japanese orthopedic association (JOA) scores, fusion rate and complications during follow-up. No significant differences between $\mathrm{m}$ - and c-TLIF were observed with respect to surgery duration $(\mathrm{P}=0.077)$, volume of blood loss $(\mathrm{P}=0.115)$, complications and the need for an additional surgery $(\mathrm{P}=0.632)$. Significant differences between the groups were observed for $\mathrm{X}$-ray exposure time $(\mathrm{P}<0.001)$ and MRI T2 relaxation times at 3 months post-surgery $(\mathrm{P}<0.001)$. At day 7 post surgery, recorded VAS and JOA scores were significantly improved in the m-TLIF compared with the c-TLIF group and non-significant differences between the groups were observed at $>1$ month follow-up. m-TLIF was a safe and effective tool in treating single-level lumbar disc herniation. However, careful attention to the surgical technique and precise anatomical knowledge were required. Further studies and refinement of
\end{abstract}

Correspondence to: Professor Jixian Qian, Department of Orthopedics, Tangdu Hospital, The Fourth Military Medical University, 1 Xinyi Road Xi'an, Shaanxi 710038, P.R. China

E-mail: qianjixian11@163.com

*Contributed equally

Key words: disc herniation, minimally invasive, transforaminal lumbar interbody fusion the surgical techniques are necessary prior to treating multiple or more extensive lesions using the m-TLIF method.

\section{Introduction}

Lumbar interbody fusion (LIF) is a standard, widely accepted surgery in the treatment of degenerative disk disease and discogenic back pain; it is used when conservative treatments have failed for $\geq 6$ months $(1,2)$. In 1940 , the first successful posterior (P) LIF was performed (3) and $\geq 85 \%$ of the 331 patients who underwent this procedure had satisfactory outcomes (4). However, this technique has disadvantages, including nerve root compression, interbody nonunion, and muscle and tissue lesions $(4,5)$.

The transforaminal (T) LIF procedure was first described by Harms and Jeszenszky (5) as an alternative to PLIF. TLIF provides access to the disc through a lateral approach following full or partial removal of the facet and preserving the contralateral joint (6). Outcomes achieved with TLIF are similar to those obtained by PLIF $(7,8)$.

Neurologic and vascular damage to the lumbar muscles have been reported when using the classic open (c-) TLIF approach $(9,10)$. To minimize muscle damage that occurs during c-TLIF, a minimally invasive (m-) TLIF procedure was first described by Foley et al (11), which avoids muscular damage to achieve fixed fusion (12). The advantages of transpedicular screws used in m-TLIF have been described extensively $(11,13)$. A meta-analysis of adverse event data suggested equivalent rates of surgical complications in patients undergoing m-TLIF compared with classic open surgery (14). To date, no comparison of $\mathrm{m}$ - and c-TLIF procedures with $>5$ years follow-up has been described in the literature (15). The objective of this study was to compare the clinical effectiveness and complications of $\mathrm{m}$ - and $\mathrm{c}$-TLIF in patients with single-level lumbar disc herniation disease and $\geq 5$ years of follow-up.

\section{Materials and methods}

Patient characteristics. From June 2008 to July 2010, 101 patients (Table I) with single-level lumbar degeneration were recruited at Tangdu Hospital (Xi'an, China) and were 
randomly divided into two groups. Patients in the m-TLIF group were treated using the Quadrant retractor and Sextant percutaneous pedicle screw systems (Medtronic Sofamor Danek, Minneapolis, MN, USA) and patients in c-TLIF were treated using the classical open procedure (Medtronic Sofamor Danek). Written informed consent was obtained from all participants prior enrollment. The clinical study was approved by the Medical Ethics Committee at Tangdu Hospital (Xi'an, China).

Patients with the following characteristics were included: i) Age, 21-60 years; ii) diagnosis, single-level lumbar disc herniation; iii) X-ray imaging, computed tomography (CT) scan and magnetic resonance imaging (MRI) results consistently explain clinical symptoms; and iv) unresponsive to conservative treatment for $\geq 6$ months prior to surgery. Exclusion criteria were as follows: i) $>1$ level lumbar degenerative disease; ii) previous lumbar surgery; iii) contraindications to surgery or with other diseases, including tumors or infections; and 5) metal allergies.

Randomization was immediately prior to surgery through a sealed envelope assigning patients to m- or c-TLIF groups. Surgeons were informed of the allocation following the induction of anesthesia. All surgical procedures were performed by a senior surgeon with assistants. Staff that provided direct postoperative care was blinded to group assignments and treatments.

Surgical procedure. Patients were positioned on a radiolucent frame under general anesthesia. A $3 \mathrm{~cm}$ longitudinal incision $3 \mathrm{~cm}$ lateral to the anatomic back midline was performed to insert the m-TLIF system. A complete facetectomy was performed and the lateral border of the dura was directly visualized. Following identifying the traversing and exiting nerve roots, an aggressive full discectomy was performed (16). Interbody distractors were used to prepare the disc space. Autologous bone graft removed from the facet was implanted in the anterior space. A single cage (PEEK OIC; Stryker Inc., Kalamazoo, MI, USA) was inserted into the disc space. The side with subjectively worse radiculopathy received the interbody graft and cage. Following the removal of the m-TLIF system, the surgeon directly palpated the pedicle entry point. A cannulated needle was advanced through the pedicle into the vertebral body under fluoroscopic guidance, followed by the insertion of a blunt-tipped guide-wire (Stryker Corporation, Kalamazoo, MI, USA) into the vertebral body. The cannulated needle was removed and the screw (Stryker Corporation) was placed following the guide-wire path. A representative case is presented in Fig. 1.

Surgery in the c-TLIF group started with a $12 \mathrm{~cm}$ incision on the anatomic back midline. A mono-portal TLIF with a unilateral subtotal facetectomy and discectomy was performed from the symptomatic side. Pedicle screws were placed and facets were decorticated prior to traversing the processes and implanting the autologous bone graft that was obtained from the laminectomy and facetectomy. A representative case is presented in Fig. 2.

Outcome measures and evaluation. The preoperative radiographic evaluation included anteroposterior, lateral and flexion-extension radiographs, CT and MRI scans. The prospectively collected data included age, gender, body mass index (BMI), location of disease, operative time, intraoperative blood loss and X-ray exposure time. Outcome measurements included radiographic results, T2 relaxation time on MRI scans and postoperative complications during follow-up. Back and leg pain was assessed by the visual analog scores (VAS) $(17,18)$ collected from the patients at 6 follow-up points (once every 6 months). Preoperative and postoperative Japanese orthopedic association (JOA) scores $(19,20)$ were compared between the groups. Completed union rates $(17,19)$ were determined by an experienced radiologist using static and dynamic X-rays at 6 follow-up times post surgery (once every 6 months).

Statistical analysis. Statistical analyses were performed using SPSS 17.0 (SPSS, Inc., Chicago, IL, USA). Continuous data are presented as the mean \pm standard deviation. Student's t-test and $\chi^{2}$ tests were performed to analyze the data. $\mathrm{P}<0.05$ was considered to indicate a statistically significant difference.

\section{Results}

Study participants. A total of 101 patients with single-level lumbar disc herniation were enrolled in the current study. Following a random, sealed envelope assignment, 52 patients were treated using $\mathrm{m}$-TLIF and 49 patients underwent c-TLIF. A total of 10 patients were lost during follow-up, 6 from the $\mathrm{m}$-TLIF and 4 from the c-TLIF group.

Baseline characteristic, including age, gender and BMI, and the levellocation of the lumbar disc herniation were not significantly different between the groups ( $\mathrm{P}>0.05$; Table I). Clinical and radiographic outcomes were collected and analyzed for $\geq 5$ years. The outcomes were recorded and evaluated preoperatively and at 7 days and 1, 3, 12, 36 and 60 months post surgery.

Measured outcomes. The mean surgery time was $105.7 \pm 16.2 \mathrm{~min}$ in the $\mathrm{m}-\mathrm{TLIF}$ and $112.7 \pm 20.7 \mathrm{~min}$ in the c-TLIF group; there was no significant difference $(\mathrm{P}=0.077$; Table II). Total intra-operative blood loss was $110.4 \pm 27.8 \mathrm{ml}$ in the m-TLIF group and $119.7 \pm 28.5 \mathrm{ml}$ in the c-TLIF group, with no significant difference between the groups $(\mathrm{P}=0.115)$. A significant difference was observed between the mean X-ray exposure times of $116.2 \pm 26.5$ and $81.7 \pm 25.1 \mathrm{sec}$ in the $\mathrm{m}$ - and c-TLIF groups, respectively $(\mathrm{P}<0.001)$. A significant difference was observed in the MRI T2 relaxation times of the operated level muscles and other soft tissues between the m- and c-TLIF groups at 3 months post surgery $(45.6 \pm 19.2$ and $85.5 \pm 26.4 \mathrm{sec}$, respectively; both $\mathrm{P}<0.001)$.

Secondary surgery. One case in the m-TLIF and two cases in the c-TLIF group were complicated by transient ipsilateral nerve root palsy during surgery. Patients were recovered completely at 3 months post surgery. In the m-TLIF group, $2 / 46(4.3 \%)$ patients required reoperation due to adjacent level degeneration at 4 and 5 years post surgery. In the c-TLIF group, $3 / 45(6.7 \%)$ patients required reoperation at 3,4 or 5 years post surgery. The incidence of reoperation was not significantly different between the groups $(\mathrm{P}=0.632$; Table II $)$. 
Table I. Patient baseline demographics.

\begin{tabular}{lccc}
\hline Variable & m-TLIF & c-TLIF & P-value \\
\hline Patients (n) & 52 & 49 & \\
Lost in follow-up (n) & 6 & 4 & \\
Completed follow-up (n) & 46 & 45 & \\
Age (years) & $57.3 \pm 10.5$ & $58.5 \pm 10.8$ & 0.604 \\
Sex (male/female) & $26 / 20$ & $27 / 18$ & 0.740 \\
Body mass index & $22.1 \pm 5.1$ & $23.2 \pm 3.4$ & 0.350 \\
Location of disease & & & \\
L2/3 & 4 & 4 & 0.971 \\
L3/4 & 7 & 5 & 0.558 \\
L4/5 & 24 & 27 & 0.452 \\
L5/S1 & 11 & 9 & 0.648 \\
Follow-up duration & $62.0 \pm 1.66$ & $62.3 \pm 1.54$ & 0.508 \\
(month) & & & \\
\hline
\end{tabular}

Data are presented as mean \pm standard deviation. TLIF, transforaminal lumbar interbody fusion; $\mathrm{m}$, minimally invasive; c, classical open.

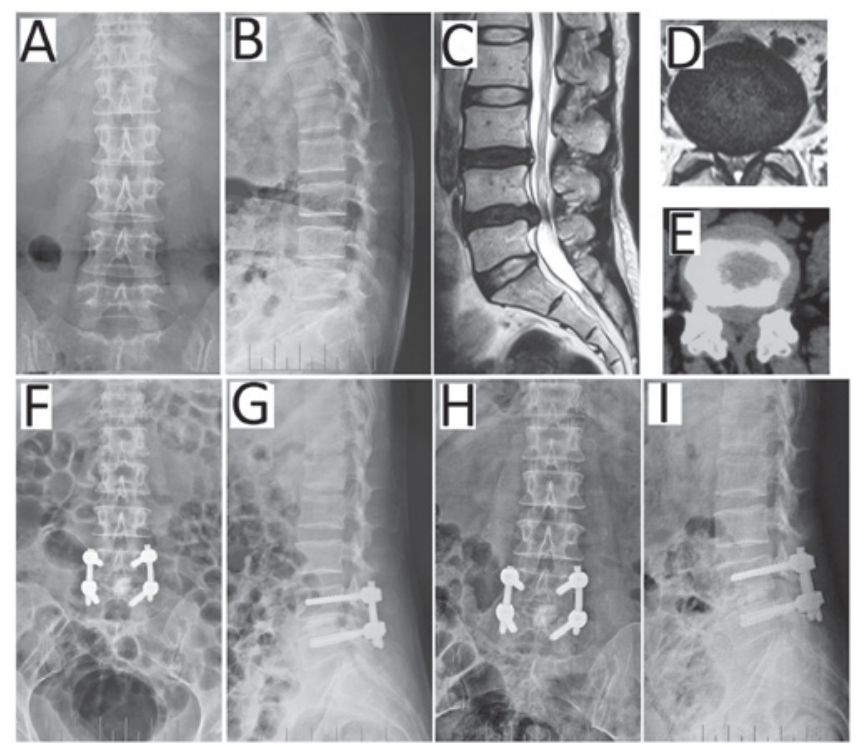

Figure 1. Representative patient (female, 50 years) with degenerative disk disease of L4/5 undergoing m-TLIF. Preoperative (A) anteroposterior and (B) lateral radiographs and (C) the MRI scan highlighting the herniated disc of L4/5. The herniated disc can be observed in the lateral left in (D) MRI and (E) computed tomography scans. At 7 days post m-TLIF with percutaneous pedicle screw fixation, $(\mathrm{F})$ anteroposterior and $(\mathrm{G})$ lateral radiographs exhibited restoration of the disc space height. $(\mathrm{H})$ Anteroposterior and (I) lateral radiographs recorded at the 12 months follow-up. m-TLIF, minimally invasive transforaminal lumbar interbody fusion; MRI, magnetic resonance imaging.

VAS. Preoperative VAS scores were not significantly different between the treatment groups. Postoperative VAS scores markedly decreased compared with the preoperative scores in m- and c-TLIF (data not shown). VAS scores at 7 days post surgery were significantly lower in the m- compared with the c-TLIF group $(\mathrm{P}<0.001$; Table III). During later follow-ups, VAS scores were not significantly different between the groups $(\mathrm{P}>0.05)$.
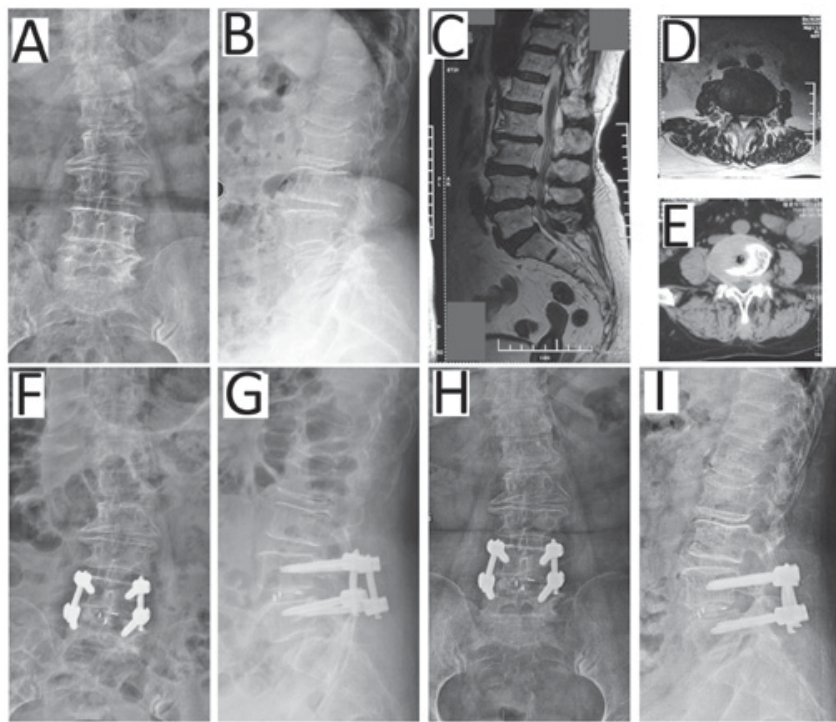

Figure 2. Representative patient (female, 58 years) with degenerative disk disease of L4/5 undergoing c-TLIF. Preoperative (A) anteroposterior and (B) lateral radiographs and $(C)$ the MRI scan highlighting the herniated disc of L4/5. The herniated disc was on the lateral right on (D) MRI and (E) computed tomography scans. At 7 days post c-TLIF with pedicle screw fixation, $(\mathrm{F})$ anteroposterior and $(\mathrm{G})$ lateral radiographs exhibited the restoration of the disc space height. $(\mathrm{H})$ Anteroposterior and (I) lateral radiographs recorded 12 months post surgery. c-TLIF, classical open transforaminal lumbar interbody fusion; MRI, magnetic resonance imaging.

$J O A$. Preoperative JOA scores were not significantly different between $\mathrm{m}$ - and c-TLIF groups. Postoperative JOA scores were markedly increased compared to the preoperative scores for $\mathrm{m}$ - and c-TLIF (data not shown). Compared with the c-TLIF group, there were no significant differences in JOA scores over time for the m-TLIF group ( $\mathrm{P}>0.05)$, except at 7 days post surgery $(\mathrm{P}=0.028$; Table IV).

\section{Discussion}

The m-TLIF procedure was first introduced by Foley et al (11) to minimize injury to the paraspinal muscles caused by the classical procedure. Since then, m-TLIF using the minimal access spinal technologies (MAST) quadrant retractor was subject of increased research interest $(12,21-23)$. Certain surgeons advocate m-TLIF to preserve the muscular and vascular lumbar structures (21-24). Consistent with previous investigations, a study reinforced the concept of minimizing lumbar muscle damage by using a minimal invasive approach, which resulted in faster and improved short-term recovery from injury (21) compared with c-TLIF. Furthermore, it was demonstrated that there is no clinically relevant difference between mini-open TLIF and c-TLIF over a 3-4 year follow-up period (22). Research by Wang et al $(23,24)$ revealed that m-TLIF efficacy and safety is similar to c-TLIF, when treating primary single-level lumbar degeneration (23) and for treating patients in revision, who were previously treated using open surgery (24). The latter study further demonstrated that $\mathrm{m}$-TLIF offered several potential advantages, including smaller incisions, less tissue injury and quicker recovery. Most studies have consistently reported the advantages of this approach (25) and the rate of fusion was not significantly 
Table II. Outcome measurements.

\begin{tabular}{|c|c|c|c|c|}
\hline Measure & m-TLIF & c-TLIF & $\mathrm{F}$ & P-value \\
\hline Surgery duration (min) & $105.7 \pm 16.2$ & $112.7 \pm 20.7$ & 3.196 & 0.077 \\
\hline Intraoperative blood loss (ml) & $110.4 \pm 27.8$ & $119.7 \pm 28.5$ & 2.530 & 0.115 \\
\hline $\mathrm{X}$-ray exposure time ${ }^{\mathrm{a}}(\mathrm{sec})$ & $116.2 \pm 26.5$ & $81.7 \pm 25.1$ & 40.842 & $<0.001$ \\
\hline MRI T2 relaxation time ${ }^{\mathrm{a}}(\mathrm{sec})$ & $45.6 \pm 19.2$ & $85.5 \pm 26.4$ & 68.533 & $<0.001$ \\
\hline VAS score ${ }^{b}$ & $0.348 \pm 0.077$ & $0.333 \pm 0.079$ & 0.017 & 0.895 \\
\hline JOA score ${ }^{b}$ & $14.024 \pm 0.280$ & $13.980 \pm 0.283$ & 0.012 & 0.912 \\
\hline Reoperation & $2 / 46$ & $3 / 45$ & 0.102 & 0.632 \\
\hline Complete fusion $^{\mathrm{b}}$ & $45 / 46$ & $44 / 45$ & 0.015 & 0.991 \\
\hline
\end{tabular}

${ }^{\mathrm{a}}$ Outcome measured at 3 months post surgery. ${ }^{\mathrm{b}}$ Outcome measured at 60 months post surgery. Data are presented as mean \pm standard deviation. TLIF, transforaminal lumbar interbody fusion; m, minimally invasive; c, classical open; MRI, magnetic resonance imaging; VAS, visual analogue scale; JOA, Japanese orthopedic association.

Table III. Correlation of VAS scores in patients treated with m- or c-TLIF over time.

\begin{tabular}{|c|c|c|c|}
\hline Variables & VAS score & $\mathrm{F}$ & P-value \\
\hline $\begin{array}{l}\text { Preoperative } \\
\text { m-TLIF } \\
\text { c-TLIF }\end{array}$ & $\begin{array}{l}7.050 \pm 0.152(6.748-7.352) \\
6.864 \pm 0.153(6.559-7.169)\end{array}$ & 0.739 & 0.392 \\
\hline $\begin{array}{l}\text { Follow-up at } 7 \text { days post surgery } \\
\text { m-TLIF } \\
\text { c-TLIF }\end{array}$ & $\begin{array}{l}3.352 \pm 0.135(3.083-3.621) \\
5.511 \pm 0.137(5.239-5.783)\end{array}$ & 125.650 & $<0.001$ \\
\hline $\begin{array}{l}\text { Follow-up at } 1 \text { month post surgery } \\
\text { m-TLIF } \\
\text { c-TLIF }\end{array}$ & $\begin{array}{l}3.117 \pm 0.118(2.883-3.351) \\
3.431 \pm 0.119(3.195-3.668)\end{array}$ & 3.510 & 0.064 \\
\hline $\begin{array}{l}\text { Follow-up at } 3 \text { months post surgery } \\
\text { m-TLIF } \\
\text { c-TLIF }\end{array}$ & $\begin{array}{l}2.043 \pm 0.087(1.870-2.217) \\
1.800 \pm 0.088(1.625-1.975)\end{array}$ & 3.857 & 0.053 \\
\hline $\begin{array}{l}\text { Follow-up at } 12 \text { months post surgery } \\
\text { m-TLIF } \\
\text { c-TLIF }\end{array}$ & $\begin{array}{l}1.783 \pm 0.118(1.549-2.017) \\
2.022 \pm 0.119(1.786-2.259)\end{array}$ & 2.046 & 0.156 \\
\hline $\begin{array}{l}\text { Follow-up at } 36 \text { months post surgery } \\
\text { m-TLIF } \\
\text { c-TLIF }\end{array}$ & $\begin{array}{l}0.587 \pm 0.106(0.375-0.798) \\
0.511 \pm 0.108(0.297-0.725)\end{array}$ & 0.251 & 0.618 \\
\hline $\begin{array}{l}\text { Follow-up at } 60 \text { months post surgery } \\
\text { m-TLIF } \\
\text { c-TLIF }\end{array}$ & $\begin{array}{l}0.348 \pm 0.077(0.194-0.501) \\
0.333 \pm 0.078(0.178-0.489)\end{array}$ & 0.017 & 0.895 \\
\hline
\end{tabular}

Data are presented as mean \pm standard deviation with a $95 \%$ confidence interval (paired t-test). TLIF, transforaminal lumbar interbody fusion; $\mathrm{m}$, minimally invasive; c, classical open; VAS, visual analogue scale.

different among the different approaches $(25,26)$. In conclusion, compared with c-TLIF, potential benefits of m-TLIF include smaller skin incisions, decreased soft tissue injury, decreased blood loss, shorter hospitalization time and earlier returns to work (21-26). The potential disadvantages of this approach include increased surgery times and radiation exposure; the procedure is more technically demanding and more experience is required (27). Accumulated radiation exposure, particularly to the hands of the surgeons should be monitored carefully. Furthermore, the cost of m-TLIF is increased compared with c-TLIF (28). Controversy remains regarding the selection of m-TLIF vs. c-TLIF. Vogelsang (29), suggested that the selection of procedure should be based on the approach that offers superior individual outcome.

To determine the effectiveness and safety of m-TLIF over an extended period, a randomized controlled study was 
Table IV. Correlation of JOA scores in patients treated with m- or c-TLIF over time.

\begin{tabular}{|c|c|c|c|}
\hline Variables & JOA score & $\mathrm{F}$ & P-value \\
\hline $\begin{array}{l}\text { Preoperative } \\
\text { m-TLIF } \\
\text { c-TLIF }\end{array}$ & $\begin{array}{l}11.941 \pm 0.202(11.539-12.343) \\
11.791 \pm 0.204(11.385-12.197)\end{array}$ & 0.273 & 0.603 \\
\hline $\begin{array}{l}\text { Follow-up at } 7 \text { days post surgery } \\
\text { m-TLIF } \\
\text { c-TLIF }\end{array}$ & $\begin{array}{l}13.952 \pm 0.264(13.428-14.477) \\
13.113 \pm 0.267(12.583-13.643)\end{array}$ & 4.997 & 0.028 \\
\hline $\begin{array}{l}\text { Follow-up at } 1 \text { month post surgery } \\
\text { m-TLIF } \\
\text { c-TLIF }\end{array}$ & $\begin{array}{l}14.154 \pm 0.275(13.609-14.700) \\
13.991 \pm 0.278(13.439-14.543)\end{array}$ & 0.175 & 0.677 \\
\hline $\begin{array}{l}\text { Follow-up at } 3 \text { months post surgery } \\
\text { m-TLIF } \\
\text { c-TLIF }\end{array}$ & $\begin{array}{l}14.135 \pm 0.212(13.713-14.556) \\
13.867 \pm 0.215(13.440-14.293)\end{array}$ & 0.789 & 0.377 \\
\hline $\begin{array}{l}\text { Follow-up at } 12 \text { months post surgery } \\
\text { m-TLIF } \\
\text { c-TLIF }\end{array}$ & $\begin{array}{l}14.096 \pm 0.275(13.550-14.642) \\
14.047 \pm 0.278(13.495-14.599)\end{array}$ & 0.016 & 0.901 \\
\hline $\begin{array}{l}\text { Follow-up at } 36 \text { months post surgery } \\
\text { m-TLIF } \\
\text { c-TLIF }\end{array}$ & $\begin{array}{l}13.870 \pm 0.251(13.371-14.368) \\
13.811 \pm 0.254(13.307-14.315)\end{array}$ & 0.027 & 0.870 \\
\hline $\begin{array}{l}\text { Follow-up at } 60 \text { months post surgery } \\
\text { m-TLIF } \\
\text { c-TLIF }\end{array}$ & $\begin{array}{l}14.024 \pm 0.280(13.468-14.580) \\
13.980 \pm 0.283(13.417-14.543)\end{array}$ & 0.012 & 0.912 \\
\hline
\end{tabular}

Data are presented as mean \pm standard deviation with a 95\% confidence interval (paired t-test). TLIF, transforaminal lumbar interbody fusion; $\mathrm{m}$, minimally invasive; c, classical open; JOA, Japanese orthopedic association.

conducted, which compared $\mathrm{m}$ - and c-TLIF in patients with single-level lumbar disc disease. It was demonstrated that there was no significant difference between these groups with respect to surgery duration, intraoperative blood loss and intraoperative complications, including transient ipsilateral nerve root palsy. These findings were not consistent with the previously reported results $(23,27)$. One explanation may be the varying experience levels of the surgeons performing the procedures. In this controlled study, a total of three patients suffered transient nerve root palsy. The variant anatomical structure of the nerve root increased the difficulty of the surgery and accidental injury to the nerve root caused the palsy. Compared with classical surgery, TLIF using the MAST quadrant retractor may decrease the length of hospitalization and result in decreased injury to the soft tissue, which manifested in a significantly decreased MRI T2 relaxation times in the operated level muscles and other soft tissues at 3 months post surgery. The X-ray exposure time in the c-TLIF group was significantly decreased compared with the m-TLIF group; describing an obvious disadvantage of latter procedure. There were no significant differences in JOA and VAS scores between the groups in follow-ups between 1 month and 5 years post surgery. However, at the 7-day post surgery follow-up, the VAS score of the m-TLIF group were decreased significantly compared with the c-TLIF group. m-TLIF was more effective in relieving pain compared with c-TLIF at early stages post surgery. As the minimally invasive retractor split the soft tissues and muscles instead of cutting them, it was possible to minimize the postoperative low back pain by reducing muscle damage. To gain a clear view during c-TILF surgery, muscles have to be cut and damaged, leading to an increased possibility of postoperative backache. Two patients in the m-TLIF and three in the c-TLIF group required reoperation due to adjacent level degeneration; the reoperation rate was not significantly different between the groups. The patients treated with the same procedure as the first time. The current study demonstrated that m-TLIF was safe to be considered an alternative to the c-TLIF procedure.

Despite the benefits, there are certain drawbacks to overcome prior to achieving effective results. First, manual experience is required and surgeons must be familiar with the novel techniques and have to be able to operate in narrow spaces. For inexperienced surgeons working in a narrow surgical field may lead to confusion regarding anatomical structures. Limitations regarding effective decompression are to further be considered. Following the completion of surgery, symptoms of nerve compression (one case of transient ipsilateral L5 nerve root palsy) may appear immediately (30), resulting from a small hematoma generated in the narrow surgical space. It is therefore important to control even minimal bleeding.

To achieve a sufficient decompression of the spinal nerves, an MRI scan must be studied carefully to determine the extent and scope of the herniation of the nucleus pulposus prior to surgery. In cases of far lateral disc disease, discectomy and 
decompression can be performed to access the midline and extraforaminal space through only one skin incision (25). Understanding the surrounding structures is important when moving and positioning the minimally invasive retractor in the extraforaminal space. To avoid damaging the nerve root during decompression, it is important to leave the inner cortical part of the caudal lamina and remove the remaining portion. The herniated nucleus pulposus is removed in the same manner as in classical surgery.

To safely place an interbody implant, an adequate laminectomy and facetectomy may be performed. A single cage was impacted into the intervertebral space following the complete removal of the nucleus pulposus through the minimally invasive retractor. Autograft bones from the laminectomy and facetectomy were placed in the interspace to augment the fusion. Isaacs et al (31) concluded that m-TLIF was safe and resulted in decreased intraoperative blood loss, postoperative pain, total narcotic use and risk of transfusion. Pedicle screws can easily be inserted percutaneously via the minimally invasive retractor systems.

In conclusion, the minimally invasive retractor system is a safe and effective tool in the treatment of single-level disc herniation. However, careful attention to the surgical technique and precise anatomical knowledge are mandatory skills for surgeons. Further studies and the refinement of surgical techniques will be required in the future to allow the treatment of multiple or more extensive lesions using m-TLIF.

\section{Acknowledgements}

Not applicable.

\section{Funding}

No funding was received.

\section{Availability of data and materials}

All data generated or analyzed during the present study are included in this published article.

\section{Authors' contributions}

JQ designed the study. HZ, HG and CZ analyzed the data and wrote the manuscript. SQ, YY and WX collected the data. All authors read and approved the final manuscript.

\section{Ethics approval and consent to participate}

The present study was approved by the Medical Ethics Committee at Tangdu Hospital (Xi'an, China). Written informed consent was obtained from all participants prior enrollment.

\section{Patient consent for publication}

Not applicable.

\section{Competing interests}

The authors declare that they have no competing interests.

\section{References}

1. Atlas SJ, Keller RB, Robson D, Deyo RA and Singer DE: Surgical and nonsurgical management of lumbar spinal stenosis: Four-year outcomes from the maine lumbar spine study. Spine (Phila Pa 1976) 25: 556-562, 2000.

2. Atlas SJ, Keller RB, Wu YA, Deyo RA and Singer DE: Long-term outcomes of surgical and nonsurgical management of lumbar spinal stenosis: 8 to 10 year results from the maine lumbar spine study. Spine (Phila Pa 1976) 30: 934-936, 2005.

3. Cloward RB: History of PLIF: Forty years of personal experience. In: Lin PM (ed). Posterior lumbar interbody fusion. Charles C Thomas, Springfield, pp58-71, 1982.

4. Cloward RB: The treatment of ruptured lumbar intervertebral discs by vertebral body fusion. I. Indications, operative technique, after care. J Neurosurg 10: 154-168, 1953.

5. Harms JG and Jeszenszky D: Die posteriore, lumbale, interkorporelle fusion in unilateraler transforaminaler technik. Oper Orthop Traumatol 10: 90-102, 1998 (In German).

6. Scheufler KM, Dohmen H and Vougioukas VI: Percutaneous transforaminal lumbar interbody fusion for the treatment of degenerative lumbar instability. Neurosurgery 60 (4 Suppl 2): S203-S213, 2007.

7. Liu J, Deng H, Long X, Chen X, Xu R and Liu Z: A comparative study of perioperative complications between transforaminal versus posterior lumbar interbody fusion in degenerative lumbar spondylolisthesis. Eur Spine J 25: 1575-1580, 2016.

8. Mehta VA, McGirt MJ, Garcés Ambrossi GL, Parker SL, Sciubba DM, Bydon A, Wolinsky JP, Gokaslan ZL and Witham TF: Trans-foraminal versus posterior lumbar interbody fusion: Comparison of surgical morbidity. Neurol Res 33: 38-42, 2011.

9. Pradhan BB, Nassar JA, Delamarter RB and Wang JC: Single-level lumbar spine fusion: A comparison of anterior and posterior approaches. J Spinal Disord Tech 15: 355-361, 2002.

10. Stevens KJ, Spenciner DB, Griffiths KL, Kim KD, Zwienenberg-Lee M, Alamin T and Bammer R: Comparison of minimally invasive and conventional open posterolateral lumbar fusion using magnetic resonance imaging and retraction pressure studies. J Spinal Disord Tech 19: 77-86, 2006.

11. Foley KT, Holly LT and Schwender JD: Minimally invasive lumbar fusion. Spine (Phila Pa 1976) 28 (15 Suppl): S26-S35, 2003.

12. Rouben D, Casnellie M and Ferguson M: Long-term durability of minimal invasive posterior transforaminal lumbar interbody fusion: A clinical and radiographic follow-up. J Spinal Disord Tech 24: 288-296, 2011.

13. Eck JC, Hodges S and Humphreys SC: Minimally invasive lumbar spinal fusion. J Am Acad Orthop Surg 15: 321-329, 2007.

14. Goldstein CL, Macwan K, Sundararajan K and Rampersaud YR: Perioperative outcomes and adverse events of minimally invasive versus open posterior lumbar fusion: Meta-analysis and systematic review. J Neurosurg Spine 24: 416-427, 2016.

15. Hackenberg L, Halm H, Bullmann V, Vieth V, Schneider M and Liljenqvist U: Transforaminal lumbar interbody fusion: A safe technique with satisfactory three to five year results. Eur Spine J 14: 551-558, 2005.

16. Mummaneni PV and Rodts GE Jr: The mini-open transforaminal lumbar interbody fusion. Neurosurgery 57 (4 Suppl): S256-S261, 2005.

17. Arts MP, Wolfs JF, Kuijlen JM and de Ruiter GC: Minimally invasive surgery versus open surgery in the treatment of lumbar spondylolisthesis: Study protocol of a multicentre, randomised controlled trial (MISOS trial). BMJ Open 7: e017882, 2017.

18. Franke J, Greiner-Perth R, Boehm H, Mahlfeld K, Grasshoff H, Allam Y and Awiszus F: Comparison of a minimally invasive procedure versus standard microscopic discotomy: A prospective randomised controlled clinical trial. Eur Spine J 18: 992-1000, 2009.

19. Minamide A, Yoshida M, Simpson AK, Nakagawa Y, Iwasaki H, Tsutsui S, Takami M, Hashizume H, Yukawa Y and Yamada H: Minimally invasive spinal decompression for degenerative lumbar spondylolisthesis and stenosis maintains stability and may avoid the need for fusion. Bone Joint J 100-B: 499-506, 2018.

20. Tian W, Yan K, Han X, Yu J, Jin P and Han X: Comparison of the clinical and radiographic results between cervical artificial disk replacement and anterior cervical fusion: A 6-year prospective nonrandomized comparative study. Clin Spine Surg 30: E578-E586, 2017.

21. Rodríguez-Vela J, Lobo-Escolar A, Joven-Aliaga E, Herrera A, Vicente J, Suñén E, Loste A and Tabuenca A: Perioperative and short-term advantages of mini-open approach for lumbar spinal fusion. Eur Spine J 18: 1194-1201, 2009. 
22. Rodríguez-Vela J, Lobo-Escolar A, Joven E, Muñoz-Marín J, Herrera A and Velilla J: Clinical outcomes of minimally invasive versus open approach for one-level transforaminal lumbar interbody fusion at the 3-to 4-year follow-up. Eur Spine J 22: 2857-2863, 2013.

23. Wang J, Zhou Y, Zhang ZF, Li CQ, Zheng WJ and Liu J: Comparison of one-level minimally invasive and open transforaminal lumbar interbody fusion in degenerative and isthmic spondylolisthesis grades 1 and 2. Eur Spine J 19: 1780-1784, 2010

24. Wang J, Zhou Y, Zhang ZF, Li CQ, Zheng WJ and Liu J: Minimally invasive or open transforaminal lumbar interbody fusion as revision surgery for patients previously treated by open discectomy and decompression of the lumbar spine. Eur Spine J 20: 623-628, 2011

25. Guan J, Bisson EF, Dailey AT, Hood RS and Schmidt MH: Comparison of clinical outcomes in the national neurosurgery quality and outcomes database for open versus minimally invasive transforaminal lumbar interbody fusion. Spine (Phila $\mathrm{Pa}$ 1976) 41: E416-E421, 2016.

26. Seng C, Siddiqui MA, Wong KP, Zhang K, Yeo W, Tan SB and Yue WM: Five-year outcomes of minimally invasive versus open transforaminal lumbar interbody fusion: A matched-pair comparison study. Spine (Phila Pa 1976) 38: 2049-2055, 2013.

27. Funao H, Ishii K, Momoshima S, Iwanami A, Hosogane N, Watanabe K, Nakamura M, Toyama Y and Matsumoto M: Surgeons' exposure to radiation in single- and multi-leve minimally invasive transforaminal lumbar interbody fusion; a prospective study. PLoS One 9: e95233, 2014.
28. Singh K, Nandyala SV, Marquez-Lara A, Fineberg SJ, Oglesby M, Pelton MA, Andersson GB, Isayeva D, Jegier BJ and Phillips FM: A perioperative cost analysis comparing single-level minimally invasive and open transforaminal lumbar interbody fusion. Spine J 14: 1694-1701, 2014.

29. Vogelsang JP: The translaminar approch in combination with a tubular retractor system for the treatment of far cranio-laterally and foraminally extruded lumbar disc herniations. Zentralbl Neurochir 68: 24-28, 2007.

30. Wang HL, Lü FZ, Jiang JY, Ma X, Xia XL and Wang LX: Minimally invasive lumbar interbody fusion via MAST Quadrant retractor versus open surgery: A prospective randomized clinical trial. Chin Med J (Engl) 124: 3868-3874, 2011.

31. Issacs RE, Podichetty VK, Santiago P, Sandhu FA, Spears J, Kelly K, Rice L and Fessler RG: Minimally invasive microendoscopy-assisted transforaminal lumbar interbody fusion with instrumentation. J Neurosurg Spine 3: 98-105, 2005.

This work is licensed under a Creative Commons Attribution-NonCommercial-NoDerivatives 4.0 International (CC BY-NC-ND 4.0) License. 